\title{
UPAYA MENINGKATKAN KEMAMPUAN KETERAMPILAN MENYIMAK DENGAN METODE IDENTIFIKASI TEMA, KALIMAT TOPIK DAN KATA KUNCI PADA MATA PELAJARAN BAHASA INDONESIA SISWA KELAS V SDN 40 BENGKULU TENGAH
}

\author{
Lentri Pensi \\ SDN 40 Bengkulu Tengah \\ lentri pensi@gmail.com
}

\begin{abstract}
Abstrak
Hasil belajar siswa kelas V SDN 40 Bengkulu Tengah pada mata pelajaran Bahasa Indonesia masih terlihat rendah. Hal ini disebabkan karena kurangnya minat perhatian dan keterlibatan siswa secara langsung dalam proses pembelajaran. Ini dapat dilihat dari 35 siswa hanya 13 orang siswa yang mencapai tsingkat penguasaan materi $70 \%$ ke atas. Untuk itu dibutuhkan suatu metode yang tepat dalam pembelajaran Bahsa Indonesia. Tujuan penelitian ini adalah untuk meningkatkan hasil belajar siswa melalui metode identifikasi tema, kalimat topic dan kata kunci pada kelas V SDN 40 Bengkulu Tengah. Subjek penelitian adalah siswa berjumlah 35 orang, sumber data penelitian diperoleh dari data kualitatif berupa data hasil observasi aktivitas guru dan siswa, serta data kuantitatif berupa data tes hasil belajar siswa. Hasil penelitian siklus I diperoleh siswa yang tuntas secara individu sebanyak 13 orang dari 35 siswa dengan ketuntasan klasikal 37,1\%. sedangkan hasil penelitian siklus II mengalami peningkatan dengan jumlah siswa yang tuntas secara individu sebanyak 20 orang dari 35 siswa dengan presentase ketuntasan klasikal sebesar 57,1\%. Hasil penelitian siklus III menunjukkan peningkatan ketuntasan siswa sebanyak 31 orang dari 35 siswa dengan presentase ketuntasan klasikal 88,6\%. Berdasarkan hasil penelitian tersebut, pembelajaran dengan menggunakan pendekatan metode identifikasi tema, kalimat topic dan kata kunci dapat meningkatkan hasil belajar siswa kelas V SDN 40 Bengkulu Tengah.
\end{abstract}

Kata kunci: Keterampilan Menyimak, Metode Identifikasi, PTK

\begin{abstract}
Student learning outcomes for fifth grade SDN 40 Bengkulu Tengah in Indonesian subjects are still low. This is due to the lack of interest in student attention and direct involvement in the learning process. This can be seen from 35 students only 13 students who achieved mastery levels of 70\% and above. For this reason, an appropriate method is needed in learning Indonesian language. The purpose of this study was to improve student learning outcomes through the method of identifying themes, topic sentences and keywords in class V SDN 40 Bengkulu Tengah. The research subjects were 35 students, the source of research data was obtained from qualitative data in the form of observations of teacher and student activities, and quantitative data in the form of student learning outcomes test data. The results of the first cycle study were obtained by students who completed individually as many as 13 people from 35 students with classical completeness $37.1 \%$. while the results of the second cycle of research have increased with the number of students who completed individually as many as 20 people from 35 students with a percentage of classical completeness of 57.1\%. The results of the third cycle showed an increase in student completeness by 31 people out of 35 students with a classical mastery percentage of 88.6\%. Based on the results of the study, learning by using the approach of identifying themes, topic sentences and keywords can improve student learning outcomes in class V SDN 40 Bengkulu Tengah.
\end{abstract}

Keywords: Listening Skills, Identification Method, PTK

\section{PENDAHULUAN}

Pembelajaran merupakan upaya membelajarkan siswa, Menurut Degeng ( 1989 ) Belajar bahasa pada hakikatnya adalah belajar komunikasi. Oleh karena itu, pembelajaran bahasa diarahkan untuk meningkatkan kemampuan pembelajaran dalam berkomunikasi, baik lisan maupun tulisan (Depdikbud, 1995). 
Pada Mata pelajaran bahasa Indonesia. Pembelajaran menyimak adalah kegiatan membelajarkan siswa agar mempunyai keterampilan menyimak dengan baik melalui latihan-latihan. Apabila terdapat bahasa yang kurang dipahami siswa maka peran guru sebagai fasilitator menjadi sangat penting untuk memberi penjelasan tentang makna arti suatu kode bahasa lisan tertentu tersebut.

Untuk mencapai tujuan pembelajaran yang telah ditetapkan, Guru menempati posisi kunci dan Strategi. Dalam menciptakan suasana belajar yang kondusif dan menyenangkan untuk mengarahkan siswa agar dapat mencapai tujuan secara optimal. Seorang guru yang profesional harus mampu menciptakan pembelajaran yang aktif, inovatif, kreatif, efektif dan menyenangkan (PAIKEM). Guru yang profesional adalah guru yang memiliki kemandirian dalam melaksanakan tanggung jawabnya.Supriyadi (1998/1999) menegaskan pentingnya kemandirian guru dalam meningkatkan kualitas pendidikan.

Menurut Jusuf Djajadisastra (1981), memilih dan menentukan metode, langkah penting yang harus selalu diperhatikan oleh guru, karena metode pembelajaran berpengaruh pada keaktifan siswa serta hasil belajar. Salah satu metode yang dapat digunakan dalam pembelajaran menyimak adalah metode identifikasi tema, kalimat topik dan kata kunci.

Metode identifikasi tema, kalimat topik, dan kata kunci ini pada prinsipnya sama. Perbedaannya terletak pada materi yang harus diidentifikasi. Identifikasi tema untuk sebuah wacana/cerita. Siswa disuruh menerka tema/topic/judulnya. Kalimat topik untuk semua paragraf. Sedangkan kata kunci untuk sebuah kalimat.

Berdasarkan pengamatan peneliti pada saat proses pembelajaran Bahasa Indonesia di SDN 40 BengkuluTengah umumnya belum begitu menantang bagi anak-anak untuk berpartisipasi aktif dalam proses belajar mengajar karena guru hanya menggunakan metode ceramah dan penugasan dalam pembelajaran Bahasa Indonesia sehingga murid menjadi jenuh atau bosan dalam belajar, dan murid menjadi sibuk dengan kegiatan yang seharusnya tidak mereka lakukan pada saat proses belajar mengajar seperti mengobrol dengan teman sebangkunya, keluar masuk dan lain-lain. Sehingga saat guru mengadakan evaluasi mayoritas siswa mendapatkan nilai di bawah standar, padahal mata pelajaran Bahasa Indonesia sangat penting karena bahasa memiliki peran sentral dalam perkembangan intelektual, sosial dan emosional peserta didik.

Untuk mengatasi permasalahan di atas, maka penulis menerapkan metode identifikasi tema, kalimat topik, dan kata kunci dalam proses pembelajaran, Adapun tujuan yang ingin dicapai dalam penelitian ini adalah untuk meningkatkan kemampuan keterampilan menyimak siswa melalui metode 36| http://jurnal.umb.ac.id/index.php/lateralisasi 
identifikasi tema, kalimat topik, dan kata kunci pada mata pelajaran Bahasa Indonesia di kelas V SDN 40 Bengkulu Tengah.

\section{METODE PENELITIAN}

Penelitian ini menggunakan metode Penelitian Tindakan Kelas (PTK). Penelitian Tindakan Kelas (PTK) merupakan salah satu upaya guru atau praktisi pendidikan uji coba inovasi pembelajaran dalam bentuk berbagai kegiatan yang dilakukan untuk memperbaiki atau meningkatkan mutu pembelajaran di kelas (Arikunto,2010). Dalam penelitian ini desain bersifat siklus dan lebih menekankan pada penelitian tindakan berulang. Penelitian ini dilakukan selama 3 siklus. Tiap siklus dilaksanakan dengan perubahan-perubahan ke arah peningkatan hasil belajar siswa. Desain penelitian yang digunakan dalam penelitian ini menggunakan desain penelitian Kemmis dan Mc. Taggart yang merupakan pengembangan dari model Kurt Levin. Dalam perencanaannya, Kemmis Menggunakan system spiral refleksi diri yang di mulai dengan rencana (planning), tindakan (action), pengamatan (obseving), refleksi (reflecting) dan perencanaan kembali yang merupakan dasar untuk suatu ancangancang pemecahan masalah.

Pola dasar model PTK menurut Kemmis dan Mc. Taggart sebagai berikut :

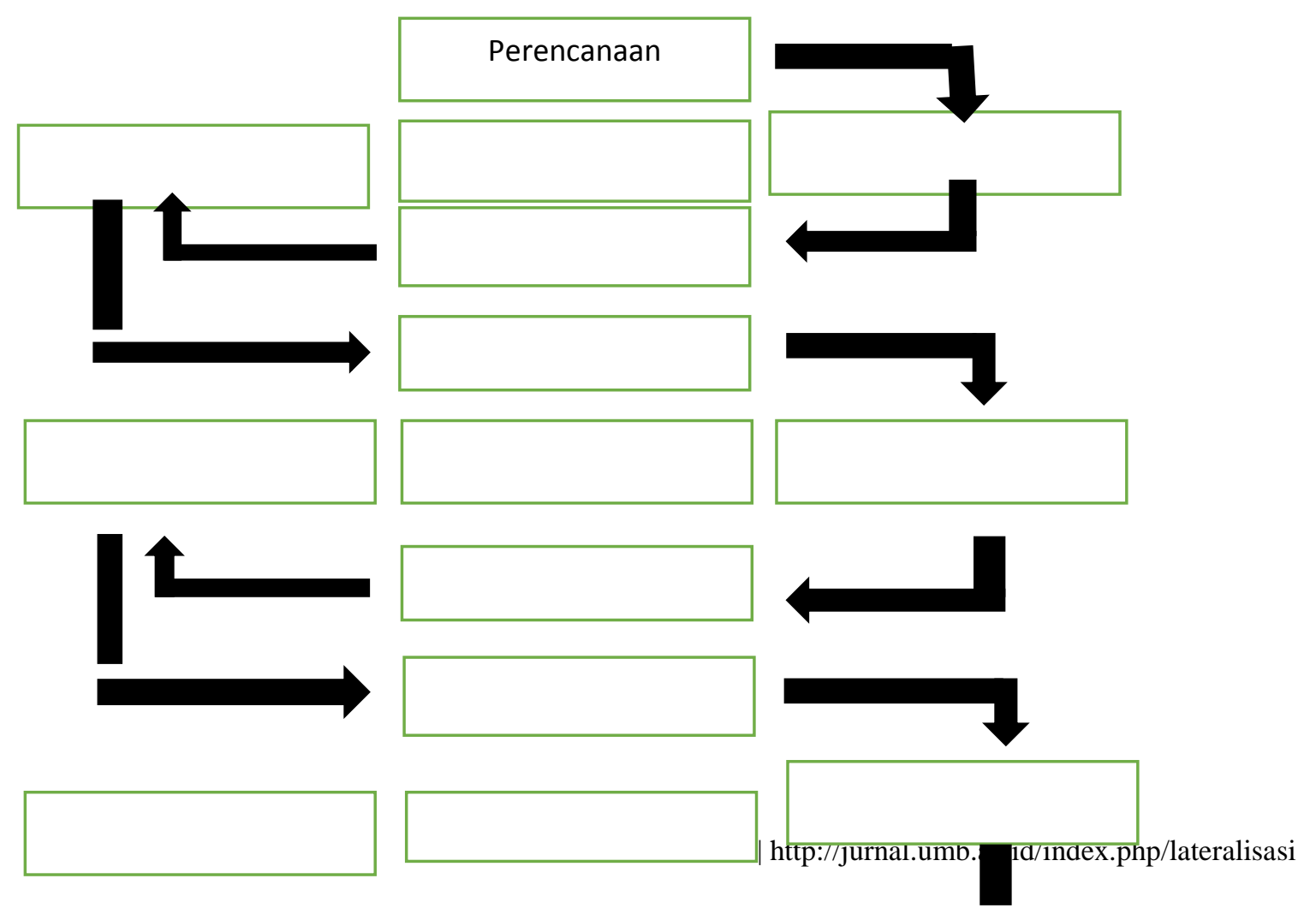




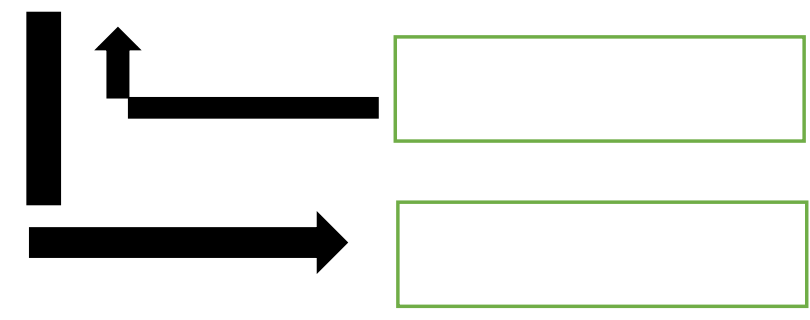

Gambar : Alur Pelaksanaan Penelitian Tindakan Kelas (Arikunto, 2006)

Penelitian Tindakan Kelas dilaksanakan mulai tanggal 14 Agustus sampai dengan 04 September 2017di kelas V SDN 40 Bengkulu Tengah. Sampel menurut Arikunto (1998) sebagian atau wakil populasi yang diteliti, Selanjutnya Arikunto (1998) memberikan penjelasan sebagai berikut : Apabila subjek kuang dari 100 lebih baik diambil semua sehingga penelitiannya merupakan penelitian populasi. Maka ditetapkan jumlah sampel dalam penelitian ini adalah 35 orang.

Menganalisis data merupakan cara yang digunakan peneliti untuk menguraikan data yang diperoleh dari penelitian supaya dapat dipahami oleh semuanya bukan hanya oleh peneliti saja tetapi juga oleh orang lain yang ingin mengetahui hasil penelitian yang sudah dilaksanakan. Pada tahap ini dilakukan analisis untuk mengetahui sejauh mana tindakan yang sudah dilakukan pada setiap siklus , sehingga dapat dijadikan sebagai bahan pertimbangan untuk diperbaiki pada tindakan siklus selanjutnya.

Menurut Ardhana12 (Dalam Moleong,2002:103) menjelaskan bahwa analisis data adalah proses mengatur urutan data, mengorganisasikannya ke dalam suatu pola, kategori, dan satuan uraian dasar. Setelah analisis selesai maka tahap selanjutnya adalah refleksi. Refleksi pada prinsipnya mencakup kegiatan analisis, interpretasi dan evaluasi alat informasi yang diperoleh dari kegiatan observasi.

Data yang terkumpul diinterpretasi , sehingga dapat diketahui keberhasilan pencapaian tujuan dan tindakan yang telah dilakukan. Interpretasi hasil disusun langkah-langkah berikutnya dalam pelaksanaan tindakan dalam skenario pembelajaran disesuaikan dengan analisis data yang terkumpul untuk perbaikan pada siklus berikutnya. Analisis data pada penelitian ini dilakukan secara kualitatif dan kuantitatif (statistik) sederhana.

Hasil dari tes didapatkan dengan berbagai cara yaitu dengan pretest dan posttest yang berisi soal essay yang harus dikerjakan oleh siswa sebelum pembelajaran dan sesudah pembelajaran. Setiap satu soal jika benar diberi bobot 20 jika siswa dapat mengerjakan semua soal dengan benar maka siswa mendapat nilai 100 . 
1) Menghitung rata-rata

Rumus untuk menghitung rata-rata :

$$
X=\frac{\sum^{X}}{N}
$$

Sumber: Sudjana, 1990

Keterangan :

$\mathrm{X}$ = Nilai Rata-rata

$\Sigma^{X}=$ Jumlah seluruh skor

$\mathrm{N} \quad=$ Banyak Siswa yang memiliki Skor

2) Ketercapaian Pembelajaran

Untuk menghitung prosentase hasil siklus dilakukan dengan perhitungan persentase menggunakan rumus :

$\begin{aligned} & \mathrm{KB}= N s / \mathrm{N} \times 100 \% \\ &-\end{aligned}$

Sumber : Purwoko, 2001

Keterangan :

$$
\begin{array}{ll}
\mathrm{KB} & =\text { Ketuntasan Belajar } \\
\mathrm{Ns} & =\text { Jumlah siswa yang mendapatkan nilai } \geq 70 \\
\mathrm{~N} & =\text { Jumlah Siswa }
\end{array}
$$

Agar data tingkat ketercapaian pembelajaran yang diperoleh mudah untuk di lihat tingkat keberhasilannya, maka semua hasil yang diperoleh dikonversikan ke dalam beberapa kategori sebagai berikut :

Tabel : Kriteria Penilaian Hasil Belajar Siswa

\begin{tabular}{|c|c|}
\hline Kriteria & Nilai \\
\hline Sangat Baik & $89<\mathrm{A} \leq 100$ \\
\hline
\end{tabular}




\begin{tabular}{|c|c|}
\hline Baik & $79<\mathrm{B} \leq 89$ \\
\hline Cukup & $70<\mathrm{C} \leq 79$ \\
\hline Perlu Bimbingan & $\mathrm{D}<70$ \\
\hline
\end{tabular}

\section{HASIL PENELITIAN DAN PEMBAHASAN}

a) Siklus I

Pada siklus I jumlah siswa yang tuntas hanya berjumlah 13 dari 35 siswa dengan persentase ketuntasan klasikal sebesar 37,1\%, masih banyak siswa yang mendapat nilai rendah dan hanya sedikit siswa yang mendapat nilai di atas 70. Dalam proses pembelajaran partisipasi aktif siswa terhadap materi pelajaran masih kurang, hal ini disebabkan karena metode pembelajaran yang dilakukan guru masih kurang. Guru hendaknya menggunakan metode yang lebih bervariasi.

b) Siklus II

Pada siklus II hasil belajar siswa yang tuntas berjumlah 20 orang dari 35 siswa dengan presentase ketuntasan klasikal sebesar 57,1\%. Peneliti melihat ada perubahan-perubahan signifikan pada diri siswa. Hampir seluruh siswa telah aktif dan bersemangat dalam mengeidentifikasi tema, kalimat topic dan kata kunci, akan tetapi masih ada juga terdapat siswa yang kurang memperhatikan dan mengganggu temannya. Oleh karena itu Guru harus lebih sering memberikan penguatan dan motivasi kepada siswa sehingga dapat meningkatkan prestasi belajarnya.

\section{C) Siklus III}

Pada siklus III siswa yang tuntas berjumlah 31 orang dari 35 siswa dengan presentase ketuntasan klasikal sebesar 88,6\%. Dari hasil pengamatan siklus III ini menunjukkan peningkatan yang lebih baik. Siswa sudah lebih bermimat dan lebih aktif dalam berdiskusi kelompok. Pemberian motivasi dan perhatian khusus kepada siswa yang kurang aktif dan kurang pintar telah memberikan hasil yang positif, terbukti dari hasil tes yang dilakukan mengalami peningkatan.

Hasil penelitian siklus I diperoleh siswa yang tuntas sebanyak 13 orang dari 35 siswa, dengan ketuntasan klasikal 37,1\% .Sedangkan hasil penelitian siklus II mengalami peningkatan dengan jumlah siswa yang tuntas sebanyak 20 orang dari 35 siswa, dengan ketuntasan klasikal sebesar 57,1\%. Hasil 
penelitian siklus III menunjukkan peningkatan hasil belajar yang lebih baik lagi, siswa yang tuntas berjumlah 31 orang dari 35 siswa dengan persentase ketuntasan klasikal sebesar 88,6\%.

Hal ini membuktikan bahwa metode identifikasi tema, kalimat topik dan kata kunci dapat meningkatkan kemampuan keterampilan menyimak siswa dan tentunya juga meningkatkan prestasi belajar siswa. yang mengalami peningkatan, hal ini dapat dilihat pada persentase ketuntasan belajar siswa pada siklus I, siklus II, dan siklus III.

\section{SIMPULAN}

Berdasarkan hasil analisis data yang diperoleh selama pelaksanaan tindakan Siklus I, Siklus II dan Siklus III, maka dapat disimpulkan bahwa dengan menggunakan metode identifikasi tema, kalimat topik, dan kata kunci pada siswa kelas V SDN 40 Bengkulu Tengah dalam mata pelajaran Bahasa Indonesia keterampilan menyimak, hasil belajar siswa mengalami peningkatan . Hal ini dapat dilihat dari analisis data selama pelaksanaan tindakan siklus I, Siklus II dan Siklus III. Pada Siklus I ketuntasan belajar siswa secara klasikal sebesar 37,1\%, pada siklus II ketuntasan belajar siswa secara klasikal sebesar $57,1 \%$ dan siklus III sebesar $88,6 \%$.

\section{DAFTAR PUSTAKA}

Agung, Purwoko. (2001). Pandauan Penelitian PTK. Semarang: Unnes.

Arikunto, S. (2006). Metode Penelitian Kualitatif. Jakarta: Bumi Aksara. - (2010). Prosedur Penelitian Suatu Pendekatan Praktik. Jakarta: Rineka Cipta.

Arikunto, Suharsimi. (1998). Prosedur Penelitian Suatu Pendekatan Praktik. Jakarta: PT. Rineka Cipta.

Departemen Pendidikan dan Kebudayaan. (1994). Kurikulum Pendidikan Dasar GBPP SD Kelas 5. Jakarta: Direktorat Pendidikan Dasar.

Departemen Pendidikan dan Kebudayaan (1999). Penyempurnaan Penyesuaian Kurikulum (suplemen GBPP) kelas 5 SD. Jakarta : Direktorat Pendidikan Dasar.

Sudjana, Nana. (2008). Penilaian Hasil Proses Belajar Mengajar. Bandung: PT. Remaja Rosdakarya.

Wardani I GAK, Wihardit Kusmaya dan Nasution Noehi. (2005). Penelitian Tindakan Kelas. Jakarta: Universitas Terbuka. 